\title{
Prey carriage varies with prey size in Cerceris fumipennis (Hymenoptera, Crabronidae)
}

\author{
Christine A. Nalepa', Whitney G. Swink' \\ I North Carolina Department of Agriculture and Consumer Services, Beneficial Insects Laboratory, 1060 Mail \\ Service Center, Raleigh, NC 27699-1060 U.S.A. \\ Corresponding author: Christine A. Nalepa (christine.nalepa@ncagr.gov)
}

Academic editor: Jack Neff | Received 22 April 2015 | Accepted 6 May 2015 | Published 11 June 2015
http://zoobank.org/7D2F39C1-083D-4ADB-AC1A-73AE5E7D3CD9

Citation: Nalepa CA, Swink WG (2015) Prey carriage varies with prey size in Cerceris fumipennis (Hymenoptera, Crabronidae). Journal of Hymenoptera Research 44: 49-55. doi: 10.3897/JHR.44.5158

\begin{abstract}
Exploitation of the hunting behavior of the solitary wasp Cerceris fumipennis is proving to be a useful method for detecting pest Buprestidae as well as for documenting buprestid diversity in eastern North America. Here we review prey carriage mechanisms in the species, and conclude that variation in prey carriage is correlated with the spectacular size range of their buprestid prey (4.9-22.3 mm length). Small prey items, including Agrilus species, are transported with the aid of a specialized morphological structure on the fifth metasomal sternite ("buprestid clamp"), resulting in a distinct curved posture during flight. Analysis of prey items from C. fumipennis in North Carolina in 2014 indicates that $30 \%$ of collected Agrilus spp. were not paralyzed prior to wasp arrival at the nest, and suggests that the buprestid clamp may function to prevent the escape of active small prey. Recognition that the curved flight posture of a female approaching her nest is a signal that she may be carrying a beetle in the genus Agrilus can improve efficiency of biosurveillance for pest Buprestidae.
\end{abstract}

\section{Keywords}

Cerceris fumipennis, buprestid clamp, prey paralysis, prey carriage, Agrilus, biosurveillance 


\section{Introduction}

The solitary, ground-dwelling wasp Cerceris fumipennis Say currently is being employed as a tool for biosurveillance of pest Buprestidae in eastern North America as well as for the documentation of regional buprestid diversity (reviewed by Swink et al. 2013, Careless et al. 2014). Any observations that contribute to more efficiently using this unique system is therefore of interest and value. Here we focus on prey carriage and paralysis by the wasp.

Current literature offers mixed reports of prey carriage by Cerceris fumipennis. Although there is general agreement that the beetle is carried in the wasps' mandibles with its head forward and venter facing up, where the beetle is grasped, and the involvement of the wasp legs in supporting the prey varies. Mueller et al. (1992) indicate that $C$. fumipennis appears to use just legs to hold larger buprestids while in flight, but Careless (2009) reports that an antenna of large beetle prey is grasped in the mandibles, with the wasp fore- and mid-legs embracing the body. Available images of $C$. fumipennis with prey are of little help, because they typically show the wasp perched on vegetation or the ground, or on final approach with her landing gear down. There are a few exceptions. Careless et al. (2009: fig. 23) picture a female in flight carrying a prey item about half her length. The wasp metasoma is extended, the thorax of the prey beetle is under her head, and the fore and middle legs are supporting the prey with the hind legs flexed and uninvolved. In video footage of a wasp hovering near her nest entrance with a large prey item (Walton 2011), it is fairly clear that all three sets of legs embrace the prey, but involvement of the mandibles is not visible.

Mueller et al. (1992) reported that smaller beetle species, including those in the genus Agrilus, are clasped about the mid-thorax with the wasp mandibles. In the course of six seasons of working with Cerceris fumipennis, however, the authors (CAN and WGS) independently noted that females coming back to the nest carrying small, Agrilus-sized beetles often can be recognized in flight by the curvature of the wasp's metasoma (Fig. 1d). Investigation into the basis of this flight posture led us to Krombein (1981), who described a "buprestid clamp" on the fifth metasomal sternite of Cerceris females in the bupresticida group, including $C$. fumipennis. He described it as a median concavity with an erect lamella at the posterior margin (Fig. 1a-c). He goes on to state that the female "grasps the head of the buprestid in her mandibles, curves the tip of her abdomen beneath and forward so that the abdominal apex of the buprestid rests in the concavity and is prevented from slipping by the erect flange. This clamp functions only with long slender buprestids such as Agrilus species." He found it a pleasing example of the correlation between structure and function.

Krombein supplied the foundation for the unique flight posture we observed, but it seemed unusual that a female transporting a small paralyzed beetle in her mandibles had need to stabilize such a light load by means of a morphological structure specific to the purpose. Here we suggest that the basis of specialized carriage of small prey by Cerceris fumipennis is that small beetles, including most Agrilus species, often are not successfully paralyzed at their collection site. 

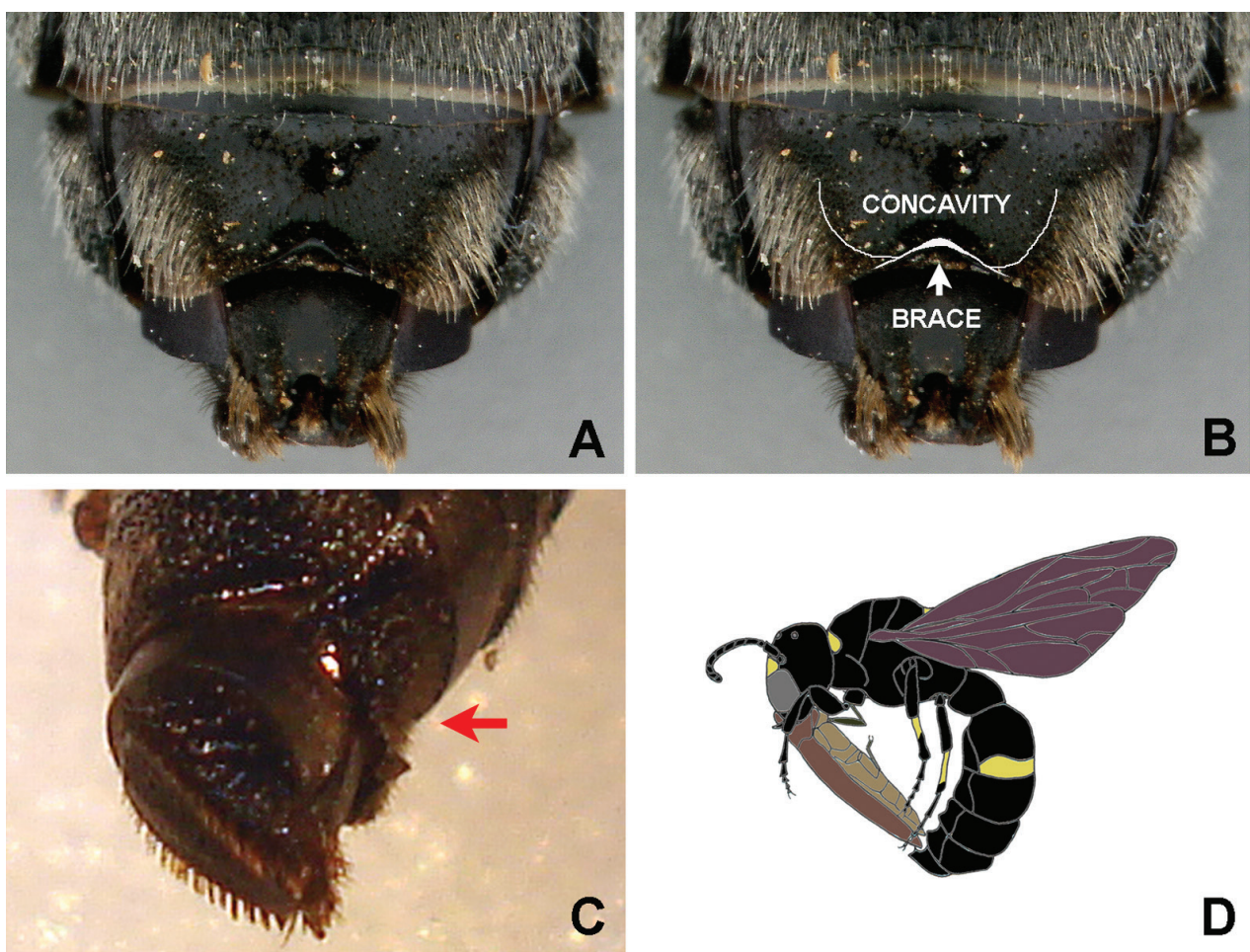

D

Figure I. Buprestid clamp in Cerceris fumipennis. (a, b) Ventral view of broadly concave median area of ventral fifth metasomal segment with an erect, cuticular process at the posterior margin acting as a brace (= buprestid clamp); (c) Ventrolateral view of buprestid clamp, showing the concavity (arrow) and brace; (d) Curved, in-flight posture of female Cerceris fumipennis using the buprestid clamp. Drawing by WGS.

\section{Methods}

During biosurveillance with Cerceris fumipennis in North Carolina during 2014, a subset of wasps captured with prey from seven widely scattered nesting aggregations were analyzed. A total of 258 females carrying prey were captured in a sweep net and the activity level of the prey item rated as paralyzed (incapable of locomotion) or not paralyzed (capable of escape). The beetle prey were then transported on ice to the laboratory where body length was measured using digital calipers (Mitutoyo Absolute Digimatic caliper $-0.01 \mathrm{~mm}$ ). Individual beetles were measured $3 x$, and the average recorded. Beetles were identified by W.G. Swink and J.P. Basham (Tennessee State University).

\section{Results}

Nine of the 258 beetles taken by Cerceris fumipennis females (3.5\%) were active and capable of escape, i.e., not paralyzed when captured. Eight of the non-paralyzed beetles were in the genus Agrilus: A. bilineatus (Weber), A. difficilis Gory, A. ruficollis (F.), and 
Table I. Body length and state of paralysis of 27 specimens of Agrilus (nine species) from seven locations (six counties) in North Carolina during 2014.

\begin{tabular}{c|c|c|c|c|c|c}
\hline Agrilus species & Length $(\mathbf{m m})$ & Paralysis? & Site & County & Latitude & Longitude \\
\hline A. arcuatus (Say) & 6.71 & + & Faith Christian Acad. & Wayne & $35.399^{\circ} \mathrm{N}$ & $78.012^{\circ} \mathrm{W}$ \\
\hline A. arcuatus & 8.00 & + & Franklinton Park & Franklin & $36.108^{\circ} \mathrm{N}$ & $78.437^{\circ} \mathrm{W}$ \\
\hline A. arcuatus & 7.04 & + & Lake Lynn Park & Wake & $35.889^{\circ} \mathrm{N}$ & $78.698^{\circ} \mathrm{W}$ \\
\hline A. arcuatus & 8.26 & + & Vance Elementary & Buncombe & $35.577^{\circ} \mathrm{N}$ & $82.600^{\circ} \mathrm{W}$ \\
\hline A. arcuatus & 7.82 & + & Vance Elementary & & & \\
\hline A. arcuatus & 8.08 & + & Vance Elementary & & & \\
\hline A. bilineatus (Weber) & 9.16 & + & Franklinton Park & & & \\
\hline A. bilineatus & 8.10 & + & Lake Lynn Park & & & \\
\hline A. bilineatus & 7.52 & - & Lake Lynn Park & & & \\
\hline A. bilineatus & 9.08 & - & Lake Lynn Park & & & \\
\hline A. bilineatus & 6.50 & - & Vance Elementary & & & \\
\hline A. bilineatus & 7.87 & - & Vance Elementary & & & \\
\hline A. bilineatus & 6.58 & + & Vance Elementary & & & \\
\hline A. bilineatus & 7.95 & - & Vance Elementary & & & \\
\hline A. bilineatus & 7.61 & + & Vance Elementary & & & \\
\hline A. bilineatus & 6.16 & + & Vance Elementary & & & \\
\hline A. bilineatus & 7.93 & + & Vance Elementary & & & \\
\hline A. bilineatus & 8.40 & + & Vance Elementary & & & \\
\hline A. cliftoni Knull & 5.86 & + & Vance Elementary & & & \\
\hline A. difficilis Gory & 10.72 & + & Luddy Park & Franklin & $36.022^{\circ} \mathrm{N}$ & $78.483^{\circ} \mathrm{W}$ \\
\hline A. difficilis & 9.25 & - & Luddy Park & & & \\
\hline A. ferrisi Dury & 10.17 & + & Luddy Park & & & \\
\hline A. pensus Horn & 9.33 & - & Meadowview MS & Surry & $36.481^{\circ} \mathrm{N}$ & $80.652^{\circ} \mathrm{W}$ \\
\hline A. quadriimpressus Ziegler & 10.56 & + & Faith Christian Acad. & & & \\
\hline A. ruficollis (F.) & 6.39 & - & McCray Recreation & Alamance & $36.171^{\circ} \mathrm{N}$ & $79.386^{\circ} \mathrm{W}$ \\
\hline A. ruficollis & 6.03 & + & McCray Recreation & & & \\
\hline A. subrobustus Saunders & 4.86 & + & Vance Elementary & & & \\
\hline
\end{tabular}

A. pensus Horn. The single non-paralyzed, non-Agrilus species captured was Brachys ovatus (Weber).

Overall, 27 Agrilus (nine species) were captured; in three species, both paralyzed and active individuals were collected from foraging wasps (Table 1). Just one individual of A. pensus was collected overall, and it was active when collected. The 27 Agrilus captured ranged from $4.9 \mathrm{~mm}$ in length (A. subrobustus) to $10.7 \mathrm{~mm}$ (A. ferrisi). There was no significant difference in the length of Agrilus that were paralyzed vs. those that were not ( $t=0.31, P=0.76$; two-sample t-test). It is notable that the smallest Agrilus captured ( $A$. subrobustus Saunders) was paralyzed. The single active Brachys ovatus measured $5.4 \mathrm{~mm}$.

\section{Discussion}

Krombein's (1981) proposal that the buprestid clamp on Cerceris fumipennis is specialized for the transport of Agrilus, combined with the inconsistent paralysis of Agrilus 
spp. reported here suggests that the two are related. Stinging behavior as well as "the state of the stung" is known to vary considerably with context (Steiner 1986), and it is likely difficult for $C$. fumipennis to manipulate small buprestids into a suitable position for stinging at the capture site. All Buprestidae are well sclerotized, and the vulnerable coxal membranes (Careless et al. 2009) of small beetles offer a miniscule target for insertion of the stinger. All buprestids furthermore exhibit death feigning (thanatosis) as a defense mechanism; they typically respond to disturbance by retracting their appendages and becoming quiescent. This allows the wasp to carry a compact and motionless beetle into its nest, even if stinging was unsuccessful (Careless 2009). We suggest that the buprestid clamp in $C$. fumipennis functions primarily to prevent the elytra from opening in small prey that may or may not be successfully paralyzed. This applies to those in the genus Agrilus (as suggested by Krombein 1981), as well as to other small species with an abdominal tip narrow enough to fit in the concavity of the clamp, such as Brachys ovatus and perhaps the alternative prey Neochlamismus bebbianae Brown (Chrysomelidae) (references in Careless et al. 2014). The latter is a small, heavily sclerotized beetle that has been taken nine times from $C$. fumipennis in North Carolina, and none to date have been paralyzed (WGS, pers. obs.).

Medium to large beetles also may be less than completely paralyzed prior to transport, but the leg embrace by the wasp assures their immobility during flight. Once in the nest, the wasp is free to assure paralysis of the prey at her leisure. Prey temporarily stored in the main burrow, prior to placement in the brood cells, continue to vary in their degree of paralysis; an Agrilus bilineatus was observed crawling out of the nest by Hook and Evans (1991). However, beetles are stung (or re-stung) prior to final placement in the brood chamber (Careless et al. 2009; Hook and Evans 1991), and prey collected from Cerceris fumipennis brood cells are always "rather thoroughly paralyzed" (Kurczewski 1984, Hook and Evans 1991).

Prey carriage plasticity in Cerceris fumipennis is related to the remarkable range of both size and shape of their buprestid prey. Careless (2009) reported that the beetles he collected were 4.9-22.3 mm in length, and those taken from C. fumipennis in North Carolina in 2014 exhibit a similar range (4.9-21.3 mm; $\mathrm{n}=258$; Nalepa and Swink, unpublished data); shape varies from the elongate, parallel-sided Agrilus to the broadly oval species of Buprestis. In medium to large beetle prey, an anterior body part of the beetle is clasped by the wasp mandibles and the number of legs involved in load support likely depends on prey length, their weight in relation to the center of gravity during wasp flight, and perhaps the degree of beetle paralysis. The load needs to be not only secure, but balanced during transport. Small prey are grasped with the mandibles, and secured via the buprestid clamp. As a whole, then, $C$. fumipennis falls into two established categories of prey carriage mechanisms depending on prey size: Mandibular 3, where the prey is held in mandibles and supported in flight with the legs, and Abdominal 2, with prey carried in flight supported by structural modifications of the apical metasomal segment (Evans 1962, O’Neill 2001: table 3-10).

Species composition of the buprestid prey of Cerceris fumipennis varies with geographic location and the plant species composition surrounding nesting aggregations. 
For example, of the 310 beetles taken from C. fumipennis nests by Evans (1971) in New York State, $84.5 \%$ were Agrilus spp., while just $8.2 \%$ of the 466 beetles collected from C. fumipennis in the Goldsboro area of North Carolina over four years were in that genus (Swink et al. 2014). Nonetheless, C. fumipennis has specific morphological and behavioral adaptations to secure and transport Agrilus, suggesting that this buprestid genus is an evolutionarily significant prey item of the wasp. Such specific adaptations to prey transport are exhibited by additional Cerceris species that hunt Buprestidae (Krombein 1981), as well as by the weevil hunting C. halone (Byers 1978).

\section{Conclusions}

The genus Agrilus contains mostly small, elongate species (4-13 mm - Paiero et al. 2012), many of which are economically important and thus the primary target of biosurveillance programs. Collections from Cerceris fumipennis can be biased against Agrilus, however, not only because of the speed of females laden with small prey, but also because of their ability to pass though, unimpeded, the plastic "Careless collars" designed to slow or stop females carrying larger beetles (see Careless et al. 2014: Fig. 1b). The latter drawback can be overcome, at least in part, by placing the hole in the collar slightly askew over the burrow entrance (Careless et al. 2014). Here we suggest that the bias can be further mitigated by expanding the search image for prey-laden incoming wasps. Cerceris fumipennis females carrying Agrilus and other small buprestid species can be recognized by their characteristic curved posture while in flight, even if the prey item is not visible. Attempts to capture these females in a sweep net prior to their arrival at the nest can help fine tune the biosurveillance system and increase the odds of detecting pest Buprestidae.

\section{Acknowledgements}

This study was funded by Forest Health Protection, USDA Forest Service (\#10-DG11083137-002). We thank Joshua Basham for his taxonomic expertise and Bob Blinn for help with photography.

\section{References}

Byers GW (1978) Nests, prey, behavior and development of Cerceris halone (Hymenoptera: Sphecidae). Journal of the Kansas Entomological Society 51: 818-831.

Careless PDS (2009) Biosurveillance: Utilizing a beetle hunting wasp (Cerceris fumipennis, Hymenoptera: Crabronidae) to detect infestations of emerald ash borers (Agrilus planipennis, Coleoptera: Buprestidae). Masters Thesis. University of Guelph, Guelph, Canada. http:// www.cerceris.info/literature.html 
Careless P, Marshall SA, Gill BD (2014) The use of Cerceris fumipennis ( Hymenoptera: Crabronidae) for surveying and monitoring emerald ash borer (Coleoptera: Buprestidae) infestations in eastern North America. Canadian Entomologist 146: 90-105. doi: 10.4039/ tce. 2013.53

Careless PD, Marshall SA, Gill BD, Appleton E, Favrin R, Kimoto T (2009) Cerceris fumipennis: A biosurveillance tool for emerald ash borer. Canadian Food Inspection Agency, Ottawa, Ontario, 1-16. http://www.cerceris.info/literature.html

Evans HE (1962) The evolution of prey-carrying mechanisms in wasps. Evolution 16: 468483. doi: $10.2307 / 2406179$

Evans HE (1971) Observations on the nesting behavior of wasps of the tribe Cercerini. Journal of the Kansas Entomological Society 44: 500-523.

Hook AW, Evans HE (1991) Prey and parasites of Cerceris fumipennis (Hymenoptera, Sphecidae) from central Texas, with description of the larva of Dasymutilla scaevola (Hymenoptera, Mutillidae). Journal of the Kansas Entomological Society 64: 257-264.

Krombein KV (1981) Biosystematic studies of Ceylonese wasps, VIII: A monograph of the Philanthidae (Hymenoptera: Sphecoidea). Smithsonian Contributions to Zoology 343: i-iii, 1-75. http://www.sil.si.edu/smithsoniancontributions/zoology/pdf_hi/sctz-0343.pdf Kurczewski FE, Miller RC (1984) Observations on the nesting of 3 species of Cerceris (Hymenoptera, Sphecidae). Florida Entomologist 67: 146-155. doi: 10.2307/3494114

Mueller UG, et al. (1992) Female size and nest defense in the digger wasp Cerceris fumipennis (Hymenoptera, Sphecidae, Philanthinae). Journal of the Kansas Entomological Society 65: 44-52.

O’Neill KM (2001) Solitary wasps: Behavior and natural history. Cornell University Press, Ithaca, New York, 1-406.

Paiero SM, Jackson MD, Jewiss-Gaines A, Kimoto T, Gill BD, Marshall SA (2012) Field guide to the jewel beetles (Coleoptera: Buprestidae) of northeastern North America. Canadian Food Inspection Agency, Ontario, Canada, 1-411.

Steiner AL (1986) Stinging behaviour of solitary wasps. In: Piek T (Ed.) Venoms of the Hymenoptera. Biochemical, pharmacological and behavioural aspects. Academic Press, London, 63-148. doi: 10.1016/b978-0-12-554770-3.50008-5

Swink WG, Nalepa CA, Basham JP (2014) Year-to-year variation in prey capture by Cerceris fumipennis (Hymenoptera: Crabronidae) at two sites in North Carolina. Annals of the Entomological Society of America 107: 1121-1125. doi: 10.1603/AN14068

Swink WG, Paiero SM, Nalepa CA (2013) Buprestidae collected as prey by the solitary, ground-nesting philanthine wasp Cerceris fumipennis (Hymenoptera: Crabronidae) in North Carolina. Annals of the Entomological Society of America 106: 111-116. doi: 10.1603/AN12113

Walton D (2011) Buprestid Hunter - Cerceris fumipennis. https://vimeo.com/19974198 [accessed 14 April 2015] 